\title{
Hospital Costs of Total Hip Arthroplasty for Developmental Dysplasia of the Hip
}

\author{
Ali Ashraf MD, A. Noelle Larson MD, \\ Hilal Maradit-Kremers MD, MSc, Walter K. Kremers PhD, \\ David G. Lewallen MD
}

Received: 26 October 2013/Accepted: 17 March 2014/Published online: 11 April 2014

(C) The Association of Bone and Joint Surgeons (B) 2014

\begin{abstract}
Background Developmental dysplasia of the hip (DDH) is a leading cause of total hip arthroplasty (THA) in younger patients. It is unknown how the hospital costs of THA in patients with DDH compare with patients with degenerative arthritis.

Questions/purposes We undertook this study to determine (1) the hospital cost and length of stay associated with primary THA in patients with dysplasia compared with nondysplastic control subjects; (2) the hospital cost and length of stay of THA in severely dysplastic hips compared with mildly dysplastic hips; and (3) perioperative complications in patients with DDH compared with patients without dysplasia.
\end{abstract}

One of the authors (DGL) receives between USD 10,000 and USD 100,000 including royalties from Zimmer, Warsaw, IN, USA; personal fees and other from Pipeline Biomedical Holdings, Cedar Knolls, NJ, USA; and Ketai Medical Devices, Hong Kong (stock and paid consultant) outside the submitted work.

All ICMJE Conflict of Interest Forms for authors and Clinical Orthopaedics and Related Research editors and board members are on file with the publication and can be viewed on request.

Each author certifies that his or her institution approved the human protocol for this investigation, that all investigations were conducted in conformity with ethical principles of research, and that informed consent for participation in the study was obtained.

A. Ashraf, A. N. Larson ( $₫)$, H. Maradit-Kremers,

D. G. Lewallen

Department of Orthopedic Surgery, Mayo Clinic,

200 1st Street SW, Rochester, MN 55905, USA

e-mail: larson.noelle@mayo.edu

H. Maradit-Kremers, W. K. Kremers

Department of Health Science Research, Mayo Clinic, Rochester, MN, USA
Methods This matched-cohort study included 354 patients undergoing primary THA for DDH and 1029 age-, sex-, and calendar year-matched patients undergoing THA for primary osteoarthritis between 2000 and 2008. DDH severity was measured by the Crowe classification. An institutional database was used to calculate the cost of care. Using line item details (date, type, frequency, and billed charge) for every procedure or service billed at our institution for each patient, bottom-up microcosting valuation techniques were used to generate standardized inflation-adjusted estimates of the cost of each service or procedure in constant dollars. Generalized linear random effects models were used to compare length of stay and costs during hospitalization and the 90-day period after surgery. Query of a longitudinal institutional database was used to identify documented complications.

Results Patients with DDH undergoing primary THA incurred higher hospital costs than patients with primary osteoarthritis (USD 16,949 versus USD 16,485, $\mathrm{p}=0.012$ ). Operating room costs (USD 3471 versus USD 3417, $\mathrm{p}=$ 0.0085) and implant costs (USD 3896 versus USD 3493, $\mathrm{p}<0.001$ ) were higher in the DDH group compared with the osteoarthritis group. Length of stay was not different between the two groups ( 4 versus 4 days, $\mathrm{p}=0.46$ ). Crowe 4 hips had higher hospital costs than Crowe 1 hips (USD 21,246 versus USD 16,345, $\mathrm{p}<0.001$ ) with an associated longer length of stay ( 5 days versus 4 days, $p=0.0011$ ) and higher implant costs (USD 4380 versus USD 3788, $\mathrm{p}=$ 0.0012). There was no detectible difference in 90-day complications in the case group compared with patients undergoing THA for osteoarthritis.

Conclusions Hospital cost of primary THA is approximately USD 450 higher in patients with DDH compared with osteoarthritis. Increased severity of dysplasia (Crowe classification) was associated with higher costs. 
Level of Evidence Level IV, economic and decision analyses. See Guidelines for Authors for a complete description of levels of evidence.

\section{Introduction}

Developmental dysplasia of the hip (DDH) represents 20\% of patients younger than 50 years undergoing THA and $2.6 \%$ of all THAs performed [9, 12, 27, 32]. DDH includes a broad range of presentations, from deficient coverage of the femoral head to frank dislocation of the hip, leading to severe degenerative arthritis in midadulthood [23, 33]. Up to $17 \%$ of patients requiring open surgical management of a dislocated hip as a child may eventually come to THA [14]. In other cases, acetabular dysplasia is often asymptomatic until patients present with degenerative changes in early to midadulthood $[23,30,31]$.

As healthcare costs rise [24], it is important to identify patient populations that consume a disproportionate amount of resources. The societal burden of THA for DDH as compared with degenerative arthritis has been only incompletely described [10, 19]. The DDH patient population undergoing THA differs from patients undergoing THA for primary hip osteoarthritis in that these patients tend to be younger, more active, and so they may place higher demands on the hip [8, 29, 35]. In addition, altered anatomy of the hip may cause increased surgical complexity at the time of arthroplasty (Fig. 1), and so this may result in increased costs. However, it is unknown whether THA for patients with DDH is more costly than THA for age- and sex-matched control subjects. If THA for patients with DDH is indeed more costly, it would be important to ascertain what contributes to the increased cost and whether this could be decreased with changes in surgical technique or perioperative care.

Therefore, we undertook this study to determine (1) the hospital cost and length of stay associated with primary THA in patients with dysplasia compared with nondysplastic control subjects; (2) the hospital cost and length of stay of THA in severely dysplastic hips compared with mildly dysplastic hips; and (3) perioperative complications in patients with DDH compared with patients without dysplasia.

\section{Patients and Methods}

This retrospective study was performed at a single tertiary referral center. Institutional review board approval was obtained for all aspects of the study, and patients who denied research authorization for use of their medical records were

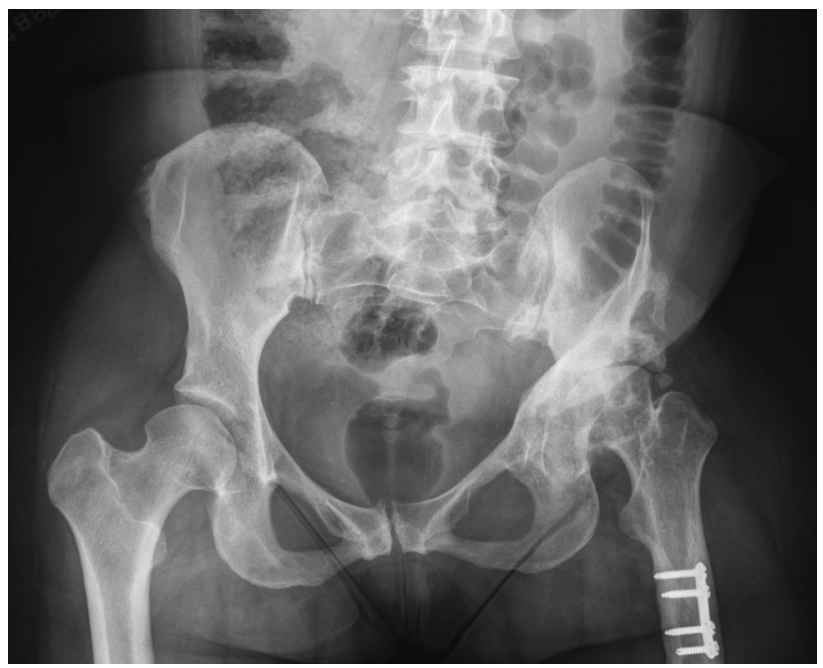

Fig. 1 A 40-year-old patient with Crowe 2 left hip dysplasia underwent THA. Note that the patient had a previous pelvic osteotomy and a femoral derotational osteotomy, which may increase the complexity and cost of the primary THA.

excluded from our analysis. Patients were identified through a comprehensive search of the institutional diagnostic and surgical databases and an institutional total joint registry. The complete medical and radiographic records of all potential patients with DDH were reviewed by the first author, and DDH-specific data elements were collected according to a prespecified protocol. DDH severity was assessed on radiographs using the Crowe classification by the first two authors [4].

During the 8-year time period between January 1, 2000, and December 31, 2008, our initial search of a longitudinal database identified a total of 588 primary THAs performed in hips noted to have hip dysplasia. On detailed medical record and preoperative radiograph review, 33 hips were excluded as a result of insufficient radiographs, lack of radiographic evidence of $\mathrm{DDH}$, or the result of lack of research authorization. An additional 40 hips were excluded as a result of concomitant diagnoses of neuromuscular disease, Legg-Calvé-Perthes disease, avascular necrosis, posttraumatic arthritis, slipped capital femoral epiphysis, impingement, protrusio, fibrous dysplasia, or tuberculosis because these diagnoses may contribute to the difficulty of the surgery, and our research focus was hips primarily affected by DDH. Of the remaining 515 hips, 103 hips were excluded from our analysis as a result of absent cost analysis data, and 44 hips were excluded as a result of less than 2-year followup (either with clinical visits and/or radiographs). Patients who underwent hip resurfacing procedures (seven hips) or a hemipelvectomy (one hip) were also excluded. No patients were treated with 


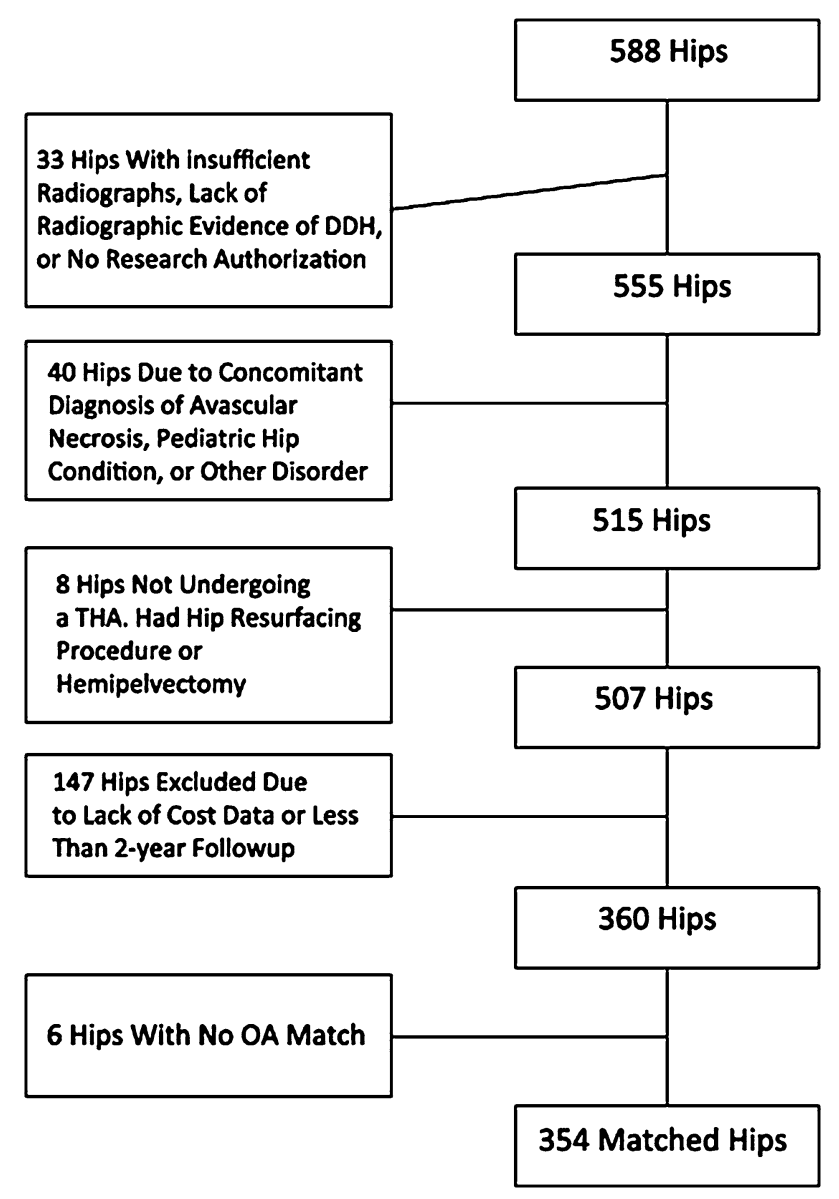

Fig. 2 Patients were selected who underwent THA for the diagnosis of developmental dysplasia. Patients with neuromuscular disease or no evidence of radiographic dysplasia were excluded. $\mathrm{OA}=$ osteoarthritis.

hemiarthroplasty (Fig. 2). Of the 360 remaining patients with DDH, appropriately matched control subjects with osteoarthritis were found for 354 patients with DDH (84\% of the original 515 eligible patients identified in the database as having a preoperative diagnosis of DDH before THA), and this represented the study cohort for patients with DDH. Of the 354 hips, 86 hips had a known history of pediatric treatment for DDH and seven hips had undergone a previous periacetabular osteotomy. Pediatric treatment included 19 closed reduction/adductor tenotomies, 11 open reductions, and 56 acetabular and/or pelvic osteotomies. These hips were included in the study cohort. The remaining 268 patients presented as adults with hip pain and radiographic features consistent with hip dysplasia. Three patients had a concomitant diagnosis of CharcotMarie-Tooth disease and were included in the analysis. For patients undergoing bilateral THA, only the first hip was included in the analysis. If a patient underwent THA for the second hip during the 90-day postoperative window, this patient was excluded from the analysis because it was difficult to determine the costs associated with each THA.

The 354 patients with DDH were individually matched by age ( \pm 5 years), sex, and calendar year to 1029 patients who underwent primary THA for the diagnosis of primary osteoarthritis (Table 1). The 1029 patients were identified by the longitudinal registry as patients undergoing THA for primary osteoarthritis. A complete review of radiographs and medical records was not carried out for patients in the control group. Differences in mean age and the percentage of female patients were in part the result of \pm 5 years agematching where some of the matched patients with osteoarthritis were slightly older than the patients with DDH and differences in number of matches per patient with DDH (ie, we were able to identify on two matches for some patients with DDH and up to four matches for some other patients with DDH). Mean body mass index was $28 \mathrm{~kg} / \mathrm{m}^{2}$ in the DDH group and $30 \mathrm{~kg} / \mathrm{m}^{2}$ in the osteoarthritis group $(\mathrm{p}<0.001)$. Comorbidities at the time of surgery were defined using administrative data (International Classification of Diseases, $9^{\text {th }}$ Revision codes) based on the Elixhauser comorbidity categories. Comorbidities were less common among patients with DDH than the matched patients with osteoarthritis (32\% versus $40 \%$ with comorbidities).

We obtained use and cost data from an institutional research database (OCHEUD), which contains standardized, inflation-adjusted costs for services and procedures billed to our institution's patients [20]. The OCHEUD database contains line item details (date, type, frequency, and billed charge) for every procedure or service billed to our institution's patients. Widely accepted bottom-up microcosting valuation techniques are used to generate standardized inflation-adjusted estimates of the cost of each service or procedure in constant dollars. OCHEUD assigns costs to resource utilization using methods similar Medicare payment models and the same methodology is applied to all patients' services, regardless of payer. Utilization is grouped and costed separately for Part A and Part B items. The distinction is methodological and does not imply that the database covers only Medicare patients. Part A items, which consist of hospital-billed services and procedures provided to inpatients such as room and board, radiology, physical therapy and supplies, are valued by multiplying the billed charge for each item by the cost center-specific cost-tocharge ratio for the year in which the service was delivered. Ratios for each cost center for each year are obtained from published Medicare cost reports. Part B items, which consist of items billed by physicians (eg, examinations and consultations, diagnostic and therapeutic procedures) and ancillary services (eg, laboratory, radiology, physical therapy), are valued using national average Medicare reimbursement rates. The algorithm applies the gross domestic product (GDP) implicit price deflator for all services to express the 
Table 1. Characteristics of the study population

\begin{tabular}{lccc}
\hline Parameter & $\begin{array}{c}\text { Patients undergoing primary } \\
\text { THA with DDH }(\mathrm{N}=354)\end{array}$ & $\begin{array}{l}\text { Matched patients undergoing primary } \\
\text { THA without DDH }(\mathrm{N}=1029)\end{array}$ \\
\hline Age (years), mean (SD) & $49(13)$ & $54(13)$ & $<0.001$ \\
Number (\%) female & $288(81 \%)$ & $765(74 \%)$ & 0.0076 \\
Body mass index $\left(\mathrm{kg} / \mathrm{m}^{2}\right)$, mean (SD) & $28(6)$ & $30(7)$ & $<0.001$ \\
Number $(\%)$ of patients with comorbidities & $113(32 \%)$ & $412(40 \%)$ & $<0.001$ \\
Number of comorbidities per patient, mean (SD) & $0.4(0.8)$ & $0.9)$ & $<0.001$ \\
\hline
\end{tabular}

$\mathrm{DDH}=$ developmental hip dysplasia.

costs for each year in 2010 constant dollars. The resulting assigned costs for all services are then adjusted to 2010 USDs using GDP implicit price deflators.

We grouped costs into clinically relevant categories such as room and board, operating room, anesthesia, implants, other supplies, and physician costs. The time window for cost data was defined as the hospitalization period and the 90-day period beginning 1 day before the THA. We did not control for blood loss or intraoperative technique (use of a surgical drain, intraoperative autologous transfusion, etc). Linear regression models were used to compare length of stay and medical costs and logistic regression was used to compare percentages of patients with complications, all adjusting for age, sex, and calendar year. Our statistical methodology is linear regression, and therefore, it is not possible to generate odds ratios or hazard ratios. Patient characteristics were expressed as means with SDs and frequencies and percentages. Total costs and specific categories of costs were presented as means with SDs. We first examined each Crowe group separately and then by combining groups. Linear models were used to compare length of stay and medical costs and logistic regression was used to compare percentages of patients with complications, all adjusting for age, sex, and calendar year. We adjusted these models for age and sex as a result of slight differences arising from imperfect matching, particularly for age. We did not adjust for comorbidities. The $\mathrm{p}$ value was set at $<0.05$ for significance.

\section{Results}

After adjusting for age, sex, and calendar year, patients with DDH undergoing primary THA experienced approximately a USD 450 increase in indexed hospital costs than matched patients with osteoarthritis (mean USD 16,949 versus USD $16,485, \mathrm{p}=0.012$; Table 2 ). This was mostly driven by operating room costs and implant costs. Operating room costs were higher in the DDH group compared with control subjects (mean USD 3471 versus USD 3417, $\mathrm{p}=0.0085$ ) as well as cost of implants (mean USD 3896 versus USD 3493, $\mathrm{p}<0.0001$ ). The total 90-day hospital costs were similar between the DDH cohort and control group (USD 17,353 versus USD 17,355, $\mathrm{p}=0.72$ ). In addition, the average length of hospital stay was similar between the two groups (4 days; range, 1-15 days versus 4 days; range, $1-10$ days; $\mathrm{p}=0.44)$.

Within the DDH cohort, Crowe 3 and 4 hips (severe dysplasia) had higher indexed hospital costs when compared with Crowe 1 and 2 hips (USD 19,537 versus USD $16,713, \mathrm{p}=0.0001$; Table 3). Total 90-day cost of Crowe 0 hip treatment was USD 16,590, Crowe 1 USD 16,857, Crowe 2 USD 18,101, Crowe 3 USD 18,296, and Crowe 4 USD 21,517.

A large portion of the increased cost of Crowe 3 and 4 hips was the result of implant costs (USD 4187 versus USD $3884, p=0.013$; Fig. 3). Patients with severe dysplasia also had longer hospital stays when compared with Crowe 1 and 2 hips ( 5 days versus 4 days, $\mathrm{p}<0.001)$. Furthermore, the total 90-day costs between these two groups of patients with DDH differed as well (USD 19,717 versus USD 17,127, $\mathrm{p}<0.001$ ). With increasing severity (Crowe 0 , Crowe 1 and 2 hips versus Crowe 3 and 4 hips), there was increased operating room time, length of stay, and all categories of costs yet, as shown by the range of values, outliers were common in all groups of patients (Table 2).

There was no significant difference in total complications for patients with DDH during the 90-day window compared with patients undergoing THA for osteoarthritis ( $11 \%$ versus $9 \%, \mathrm{p}=0.20$; Table 4 ). The most common complication was periprosthetic fracture. In the 90-day window, a total of $32(9 \%)$ patients with DDH sustained a bone or periprosthetic fracture as compared with $52(5 \%)$ patients among patients with osteoarthritis $(\mathrm{p}=0.023)$.

\section{Discussion}

Although DDH represents a small proportion of THA diagnoses, THA for DDH may require a large healthcare expenditure because of the complexity of these procedures, which may be compounded by the young age of the patients. In this study, we sought to determine the cost of primary THA in patients with a history of DDH compared 
Table 2. Length of stay and costs among patients undergoing THA with developmental dysplasia of the hip (DDH) and matched patients with osteoarthritis

\begin{tabular}{|c|c|c|c|c|c|c|}
\hline \multirow[t]{2}{*}{ Parameter } & \multicolumn{4}{|c|}{ Patients undergoing THA with DDH } & \multirow{2}{*}{$\begin{array}{l}\text { Matched patients } \\
\text { undergoing THA } \\
\text { with osteoarthritis } \\
(\mathrm{N}=1029)\end{array}$} & \multirow[t]{2}{*}{$\mathrm{p}$ value* } \\
\hline & $\begin{array}{l}\text { Crowe } 0 \\
(\mathrm{~N}=15)\end{array}$ & $\begin{array}{l}\text { Crowe } 1+2 \\
(\mathrm{~N}=305)\end{array}$ & $\begin{array}{l}\text { Crowe } 3+4 \\
(\mathrm{~N}=34)\end{array}$ & $\begin{array}{l}\text { Overall } \\
(\mathrm{N}=354)\end{array}$ & & \\
\hline \multicolumn{7}{|c|}{ Length of stay (days) } \\
\hline Mean $( \pm \mathrm{SD})$ & $4(0.6)$ & $4(1.4)$ & $5(1.0)$ & $4(1.3)$ & $4(1.2)$ & $0.44 /<0.001$ \\
\hline Median (range) & $4(3-5)$ & $4(1-15)$ & $4(3-7)$ & $4(1-15)$ & $4(1-10)$ & \\
\hline \multicolumn{7}{|l|}{ OR time (minutes) } \\
\hline Mean $( \pm$ SD) & $166(55)$ & $1567(51)$ & $205(65)$ & $161(54)$ & $146(55)$ & $0.0011 /<0.001$ \\
\hline Median (range) & $174(79-280)$ & $153(34-302)$ & $196(114-325)$ & $157(34-325)$ & $140(24-425)$ & \\
\hline \multicolumn{7}{|l|}{ Costs (USD) } \\
\hline \multicolumn{7}{|c|}{ Index hospitalization cost } \\
\hline Mean $( \pm \mathrm{SD})$ & $15,892(1569)$ & $16,713(2779)$ & $19,537(3337)$ & $16,949(2920)$ & $16,485(2952)$ & $0.012 /<0.001$ \\
\hline Median (range) & $15,372(13,482-19,822)$ & $16,450(8985-39,060)$ & $19,054(14,515-27,657)$ & $16,548(8985-39,060)$ & $16,073(10,448-40,587)$ & \\
\hline \multicolumn{7}{|l|}{ OR cost } \\
\hline Mean $( \pm$ SD) & $3380(323)$ & $3427(548)$ & $3815(515)$ & $3471(548)$ & $3417(493)$ & $0.0085 /<0.001$ \\
\hline Median (range) & $3322(2774-4069)$ & $3403(461-5020)$ & $3719(3061-4985)$ & $3423(461-5020)$ & $3386(2081-7067)$ & \\
\hline \multicolumn{7}{|l|}{ Implant cost } \\
\hline Mean $( \pm$ SD) & $3465(764)$ & $3884(1146)$ & $4187(924)$ & $3896(1118)$ & $3493(1090)$ & $<0.001 / 0.013$ \\
\hline Median (range) & $3364(2261-4731)$ & 3893 (809-8394) & $4071(2065-6070)$ & 3893 (809-8394) & $3448(88-8564)$ & \\
\hline \multicolumn{7}{|l|}{ Total 90-day cost } \\
\hline Mean $( \pm \mathrm{SD})$ & $16,590(2736)$ & $17,127(, 490)$ & 19,717 (3478) & 17,353 (3539) & $17,355(5268)$ & $0.72 /<0.001$ \\
\hline Median (range) & $15,941(13,520-25,138)$ & $16,602(9026-39,176)$ & $19,176(14,553-27,657)$ & $16,694(9026-39,176)$ & $16,288(10,448-71,661)$ & \\
\hline
\end{tabular}

* p values comparing DDH with osteoarthritis adjusting for age and year or surgery Crowe classification groups among themselves; $\mathrm{OR}=$ operating room.

Table 3. Length of stay and costs (USD) after THA by severity of development dysplasia of the hip

\begin{tabular}{lrrrrr}
\hline Parameter & Crowe 0 & Crowe 1 & Crowe 2 & Crowe 3 & Crowe 4 \\
\hline Length of stay (days) & 4 & 4 & 5 & 5 & 5 \\
Index hospitalization cost & 15,892 & 16,345 & 18,042 & 18,189 & 21,246 \\
OR cost & 3380 & 3389 & 3613 & 3690 & 3975 \\
Implant cost & 3465 & 3788 & 4233 & 4036 & $<0016$ \\
Total 90-day cost & 16,590 & 16,857 & 18,101 & 18,296 & 21,517 \\
\hline
\end{tabular}

$\mathrm{OR}=$ operating room.

with age- and sex-matched patients who did not have a diagnosis of DDH. We also examined the cost difference between severely dysplastic hips versus mildly dysplastic hips and the 90-day complications associated with THA in this patient population.

Our study has several limitations. Patients who underwent bilateral procedures were not included in our cost analysis. There is an obvious higher cost for patients who had simultaneous or staged bilateral procedures. Two raters (ANL, AA) evaluated the radiographs for patients with DDH regarding qualification and Crowe classification, but no inter- or intrarater reliability assessment was performed. No radiograph review was undertaken for 1029 control patients. Thus, it is possible that some of the patients with primary osteoarthritis had occult hip dysplasia, which was not detected by our registry. The matched cohort study method selected predominantly young female control patients, and it is possible that some of these control patients had undiagnosed dysplasia. A percentage of the patients with DDH had childhood surgery. The rates of childhood surgery in the primary osteoarthritis group are not known, but presumably would be lower than the rates of childhood surgery among the patients with DDH. Although our bottom-up microcosting methodology is the most accurate costing methodology when detailed line item data are available (which is rarely feasible in other 

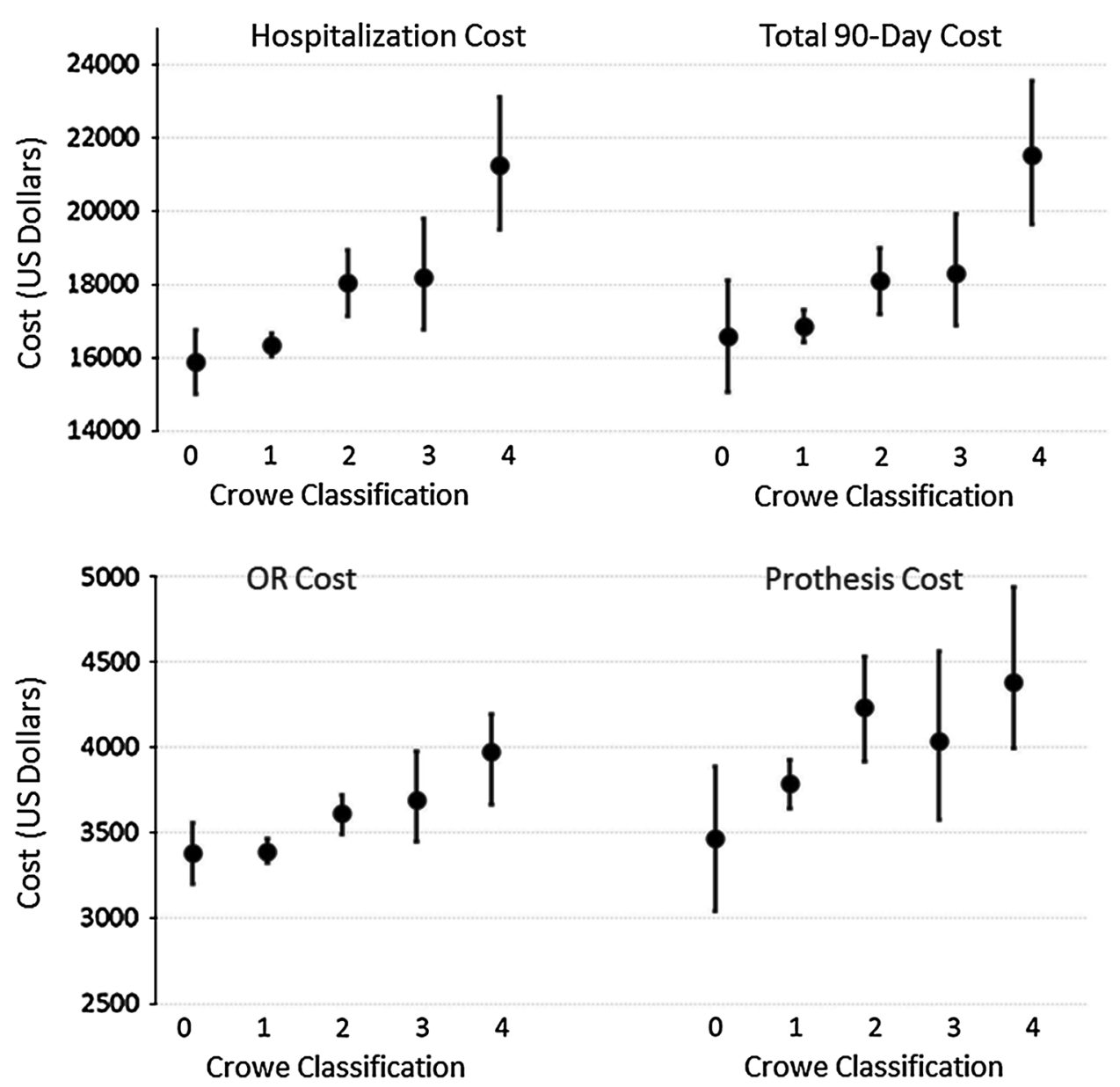

Fig. 3 The cost of THA (hospitalization, operating room, total, prosthesis) was increased in patients with more severe dysplasia. $\mathrm{OR}=$ operating room.

Table 4. Ninety-day complications

\begin{tabular}{|c|c|c|c|}
\hline Parameters & $\begin{array}{l}\text { Patients undergoing primary } \\
\text { THA with DDH }(\mathrm{N}=354)\end{array}$ & $\begin{array}{l}\text { Matched patients undergoing primary } \\
\text { THA without DDH }(\mathrm{N}=1029)\end{array}$ & $\mathrm{p}$ value \\
\hline $\begin{array}{l}\text { Number }(\%) \text { of patients who experienced at } \\
\text { least one complication }\end{array}$ & $42(11 \%)$ & $97(9 \%)$ & 0.19 \\
\hline Deep and/or superficial infection & $0(0 \%)$ & $12(1 \%)$ & N/A \\
\hline Vascular complication & $4(1 \%)$ & $15(2 \%)$ & 0.76 \\
\hline Thromboembolic complication & $5(1 \%)$ & $13(1 \%)$ & 0.34 \\
\hline Bone and/or prosthesis fracture & $32(9 \%)$ & $52(5 \%)$ & 0.023 \\
\hline
\end{tabular}

$\mathrm{DDH}=$ developmental dysplasia of the hip; N/A = not applicable.

settings), there are difficulties arising from using line item administrative claims data for costing studies. For example, certain services appear in the line item data without a valid Current Procedural Terminology (CPT) 4 code. Some of these services such as room and board and intensive care unit can be identified using the Uniform billing revenue codes plus the feeder keys, but not all. Some CPT 4 codes do not have defined reimbursement. There may be hospital services billed with separate technical and professional components. Otherwise, we took into account a number of other common billing features in THA. For example, when surgery CPT 4 codes appear on more than one line representing more than one surgeon, we reviewed the modifiers (to figure out whether an assistant or a cosurgeon was involved) counted as one per surgery. If a procedure code appears twice with modifiers RT (right side) and LT (left 
side), we counted both. Our cost analysis does not include the need for future revision surgeries or contributions from patient-reported outcomes [8, 29]. Our minimum 2-year followup time did not provide enough information to appropriately assess the rate and costs of revision surgery. Furthermore, we only examined the hospital and 90-day direct medical costs associated with surgery and did not include outpatient and indirect costs to the patient such as outpatient physical therapy, lost labor, and rehabilitation center admissions, which can be substantial around the time of THA. All procedures were performed at a tertiary referral center and may not represent the results and costs of DDH treatment at other practices.

We found that the hospital cost of THA was approximately USD 450 higher in patients with DDH compared with patients with primary osteoarthritis. To our knowledge, this is the first study reporting on the cost of THA in patients with DDH. There have been numerous studies evaluating the costs of THA as a procedure compared with staged procedures, resurfacing or hemiarthroplasty $[3,5-7$, $11,13,15,16,21,22,25,26]$; however, none specifically looked at the DDH patient population. Other studies have evaluated the quality of life in patients with hip dysplasia treated with THA but have not evaluated costs [2, 8, 29]. Based on our study, we found that patients with DDH who undergo THA have comparable total 90-day costs as ageand sex-matched patients with primary osteoarthritis. Differences in costs were the result of primarily increased operative and implant costs. Gioe et al. reported no improved outcomes with premium implants compared with standard components but did not specifically evaluate patients with dysplasia [11]. Rising implant costs have been associated with the increased cost of THA in general [15]. Specialized implants, however, are routinely used for patients with dysplasia to accommodate a narrowed proximal femoral canal, excessive femoral anteversion, and the shallow acetabulum [28].

In addition, we determined that patients with severe dysplasia have increased hospital costs compared with patients with mild dysplasia. Contributors to increased costs for patients with severe dysplasia again included length of stay, implant cost, and operative cost. It is well known that Crowe III and IV hip pose specialized reconstructive challenges, likely increasing the cost of care [17, 18, 34].

Finally, we assessed the rate of perioperative complications within the 90-day window for patients undergoing THA for DDH versus osteoarthritis. We did not find any difference in the rates of complications in patient with a history of DDH compared with osteoarthritis. This is similar to other short-term reports [1]. However, long-term need for revision surgery was not assessed in our study, although other studies have not found an increased rate of revision surgery for patients undergoing THA for dysplasia
[32]. There was a decreased rate of periprosthetic fracture in patients with a history of DDH, the treatment of which is known to be very costly [21].

In summary, patients with DDH have approximately USD 450 higher hospital costs for THA compared with patients with osteoarthritis as a result of higher implant and operative costs. This represents only a small percentage of overall 90-day hospital costs. Furthermore, THA performed for severe Crowe 3 and 4 hips resulted in longer length of stay and higher overall costs compared with THA undertaken for Crowe 1 and 2 hips. There was no detected difference in rates of early complications for patients undergoing THA for dysplasia compared with a matched cohort.

\section{References}

1. Boyle MJ, Frampton CM, Crawford HA. Early results of total hip arthroplasty in patients with developmental dysplasia of the hip compared with patients with osteoarthritis. J Arthroplasty. 2012;27:386-390.

2. Boyle MJ, Singleton N, Frampton CM, Muir D. Functional response to total hip arthroplasty in patients with hip dysplasia. ANZ J Surg. 2013;83:554-558.

3. Bozic KJ, Morshed S, Silverstein MD, Rubash HE, Kahn JG. Use of cost-effectiveness analysis to evaluate new technologies in orthopaedics. The case of alternative bearing surfaces in total hip arthroplasty. J Bone Joint Surg Am. 2006;88:706-714.

4. Crowe JF, Mani VJ, Ranawat CS. Total hip replacement in congenital dislocation and dysplasia of the hip. J Bone Joint Surg Am. 1979;61:15-23.

5. Daigle ME, Weinstein AM, Katz JN, Losina E. The cost-effectiveness of total joint arthroplasty: a systematic review of published literature. Best Pract Res Clin Rheumatol. 2012;26:649-658.

6. Dreghorn CR, Roughneen P, Graham J, Hamblen DL. The real cost of joint replacement. Br Med J (Clin Res Ed). 1986;292:1636-1637.

7. Edlin R, Tubeuf S, Achten J, Parsons N, Costa M. Cost-effectiveness of total hip arthroplasty versus resurfacing arthroplasty: economic evaluation alongside a clinical trial. BMJ Open. 2012;2. pii: e001162.

8. Engesaeter IO, Lehmann T, Laborie LB, Lie SA, Rosendahl K, Engesaeter LB. Total hip replacement in young adults with hip dysplasia: age at diagnosis, previous treatment, quality of life, and validation of diagnoses reported to the Norwegian Arthroplasty Register between 1987 and 2007. Acta Orthop. 2011;82:149-154.

9. Felson DT, Zhang Y. An update on the epidemiology of knee and hip osteoarthritis with a view to prevention. Arthritis Rheum. 1998;41:1343-1355.

10. Gent E, Clarke NM. Joint replacement for sequelae of childhood hip disorders. J Pediatr Orthop. 2004;24:235-240.

11. Gioe TJ, Sharma A, Tatman P, Mehle S. Do 'premium' joint implants add value? Analysis of high cost joint implants in a community registry. Clin Orthop Relat Res. 2011;469:48-54.

12. Harris WH. Etiology of osteoarthritis of the hip. Clin Orthop Relat Res. 1986;213:20-33.

13. Hawker GA, Badley EM, Croxford R, Coyte PC, Glazier RH, Guan J, Harvey BJ, Williams JI, Wright JG. A population-based nested case-control study of the costs of hip and knee replacement surgery. Med Care. 2009;47:732-741.

14. Holman J, Carroll KL, Murray KA, Macleod LM, Roach JW. Longterm follow-up of open reduction surgery for developmental dislocation of the hip. J Pediatr Orthop. 2012;32:121-124. 
15. Kelly MP, Bozic KJ. Cost drivers in total hip arthroplasty: effects of procedure volume and implant selling price. Am J Orthop (Belle Mead NJ). 2009;38:E1-4.

16. Kim S. Changes in surgical loads and economic burden of hip and knee replacements in the US: 1997-2004. Arthritis Rheum. 2008;59:481-488.

17. Krych AJ, Howard JL, Trousdale RT, Cabanela ME, Berry DJ. Total hip arthroplasty with shortening subtrochanteric osteotomy in Crowe type-IV developmental dysplasia. J Bone Joint Surg Am. 2009;91:2213-2221.

18. Lei P, Hu Y, Cai P, Xie J, Yang X, Wang L. Greater trochanter osteotomy with cementless THA for Crowe type IV DDH. Orthopedics. 2013;36:e601-605.

19. Mahan ST, Katz JN, Kim YJ. To screen or not to screen? A decision analysis of the utility of screening for developmental dysplasia of the hip. J Bone Joint Surg Am. 2009;91:1705-1719.

20. Maradit Kremers H, Visscher SL, Moriarty JP, Reinalda MS, Kremers WK, Naessens JM, Lewallen DG. Determinants of direct medical costs in primary and revision total knee arthroplasty. Clin Orthop Relat Res. 2013;471:206-214.

21. March L, Cross M, Tribe K, Lapsley H, Courtenay B, Brooks P. Cost of joint replacement surgery for osteoarthritis: the patients' perspective. J Rheumatol. 2002;29:1006-1014.

22. Meyers SJ, Reuben JD, Cox DD, Watson M. Inpatient cost of primary total joint arthroplasty. J Arthroplasty. 1996;11:281-285.

23. Noordin S, Umer M, Hafeez K, Nawaz H. Developmental dysplasia of the hip. Orthop Rev (Pavia). 2010;2:e19.

24. Orszag PR, Ellis P. The challenge of rising health care costs-a view from the Congressional Budget Office. $N$ Engl J Med. 2007;357:1793-1795.

25. Reuben JD, Meyers SJ, Cox DD, Elliott M, Watson M, Shim SD. Cost comparison between bilateral simultaneous, staged, and unilateral total joint arthroplasty. J Arthroplasty. 1998;13: $172-179$.
26. Stargardt T. Health service costs in Europe: cost and reimbursement of primary hip replacement in nine countries. Health Econ. 2008;17:S9-20.

27. Takenaga RK, Callaghan JJ, Bedard NA, Liu SS, Klaassen AL, Pedersen DR. Cementless total hip arthroplasty in patients fifty years of age or younger: a minimum ten-year follow-up. $J$ Bone Joint Surg Am. 2012;94:2153-2159.

28. Tamegai H, Otani T, Fujii H, Kawaguchi Y, Hayama T, Marumo K. A modified S-ROM stem in primary total hip arthroplasty for developmental dysplasia of the hip. J Arthroplasty. 2013;28:1741-1745.

29. Tellini A, Ciccone V, Blonna D, Rossi R, Marmotti A, Castoldi F. Quality of life evaluation in patients affected by osteoarthritis secondary to congenital hip dysplasia after total hip replacement. J Orthop Traumatol. 2008;9:155-158.

30. Terjesen T, Bredland T, Berg V. Ultrasound for hip assessment in the newborn. J Bone Joint Surg Br. 1989;71:767-773.

31. Terjesen T, Holen KJ, Tegnander A. Hip abnormalities detected by ultrasound in clinically normal newborn infants. J Bone Joint Surg Br. 1996;78:636-640.

32. Thillemann TM, Pedersen AB, Johnsen SP, Soballe K. Implant survival after primary total hip arthroplasty due to childhood hip disorders: results from the Danish Hip Arthroplasty Registry. Acta Orthop. 2008;79:769-776.

33. Wedge JH, Wasylenko MJ. The natural history of congenital dislocation of the hip: a critical review. Clin Orthop Relat Res. 1978;137:154-162.

34. Yan F, Chen G, Yang L, He R, Gu L, Wang F. A reduction technique of arthroplasty without subtrochanteric femoral shortening osteotomy for the treatment of developmental high dislocation of hip: a case series of 28 hips. J Arthroplasty. 2013 Dec 4 [Epub ahead of print].

35. Yang S, Cui Q. Total hip arthroplasty in developmental dysplasia of the hip: review of anatomy, techniques and outcomes. World $J$ Orthop. 2012;3:42-48. 